\title{
AGRAVOS E RISCOS À SAÚDE DO IDOSO RELACIONADO AO SISTEMA CARDIOVASCULAR: HIPERTENSÃO ARTERIAL E ACIDENTE VASCULAR CEREBRAL
}

\author{
Claudia C. Abreu de Assis ${ }^{2}$, José Augusto S. da Silva², Júlia Tavares S. Paiva², Luíza Barbosa \\ Couto $^{2}$, Silamayneer Silva F. de Souza ${ }^{2}$, Lílian P. Facin de Campos ${ }^{1}$
}

(1) Pesquisadora do Laboratório de Estudos em Saúde Pública (NUPENSP/ISECENSA) - Institutos Superiores de Ensino do CENSA - ISECENSA -

Rua Salvador Correa, 139, Centro, Campos dos Goytacazes, RJ, Brasil; (2) Acadêmico (a) do Curso de Enfermagem do ISECENSA.

O presente trabalho é uma atividade de ensino desenvolvida no decorrer do $5^{\circ}$ período da graduação de enfermagem sobre os agravos e riscos à saúde do idoso relacionado ao sistema cardiovascular: hipertensão arterial e acidente vascular cerebral para criar ações e estratégias que possam contribuir com à saúde do idoso relacionado ao surgimento de patologias que possam acometer o sistema cardiovascular. Com esse intuito, o trabalho foi apresentado como seminário e nota de atividade parcial da disciplina cuidados de enfermagem ao cliente idoso tendo em vista que o tema é de extrema importância para desenvolver a assistência de enfermagem prestada à saúde do idoso relacionado ao acometimento do sistema cardiovascular. Espera-se que possa contribuir com o planejamento de ações e estratégias para a promoção, prevenção, recuperação e reabilitação do cliente idoso de uma patologia ligada ao sistema cardiovascular. O presente estudo para a preparação do seminário tem como objetivos ressaltar a importância do planejamento de ações e estratégias que possam ajudar a diminuir os riscos e agravos que acometem o sistema cardiovascular do idoso. E a importância da assistência de enfermagem juntamente com toda equipe multiprofissional, promover uma boa qualidade de vida e bem estar através de suas orientações. $O$ principal método de proposta é de passar para o público presente informações que possam estar contribuindo com a assistência de enfermagem voltada para a saúde do idoso e que possa tentar diminuir esses riscos e agravos através do incentivo à prática de atividades físicas e uma alimentação saudável e equilibrada. Conclui-se que, o processo de envelhecimento da população é acompanhado por modificações no padrão de perdas estruturais e funcionais, tendo como resultado maior a exposição dos idosos aos fatores de riscos e agravos crônicos não transmissíveis, principalmente, o surgimento das patologias que acometem o sistema cardiovascular. A hipertensão arterial tem se mostrado como um fator de risco grave para a saúde do idoso podendo comprometer o sistema cardiovascular levando a ocorrência de um acidente vascular cerebral (AVC) ou as disfunções cardiovasculares como: arritmias, insuficiência cardíaca congestiva (ICC), arterosclerose e infarto do miocárdio.

Palavras-Chave: Saúde do Idoso; Hipertensão; Acidente Vascular Cerebral (AVC). 